\title{
Distribution and dry deposition of alternative and legacy perfluoroalkyl and polyfluoroalkyl substances in the air above the Bohai and Yellow Seas, China
}

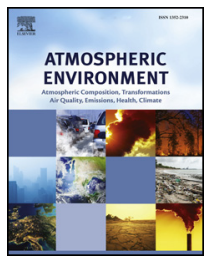

\author{
Xiangguang Fang ${ }^{\mathrm{a}, 1}$, Qi Wang ${ }^{\mathrm{a}, 1}$, Zhen Zhao ${ }^{\mathrm{a}, \mathrm{b}, *}$, Jianhui Tang ${ }^{\mathrm{c}}$, Chongguo Tian $^{\mathrm{c}}$, Yiming Yao ${ }^{\mathrm{a}}$, \\ Junchao $\mathrm{Yu}^{\mathrm{a}}$, Hongwen $\mathrm{Sun}^{\mathrm{a}}$ \\ ${ }^{a}$ MOE Key Laboratory of Pollution Processes and Environment Criteria, College of Environmental Science and Engineering, Nankai University, Tianjin, 300350, China \\ ${ }^{\mathrm{b}}$ State Key Laboratory of Organic Geochemistry, Guangzhou Institute of Geochemistry, Chinese Academy of Sciences, Guangzhou, 510640, China \\ ${ }^{\mathrm{c}}$ Key Laboratory of Coastal Environmental Processes \& Ecological Remediation, Yantai Institute of Coastal Zone Research, Yantai, 264003, China
}

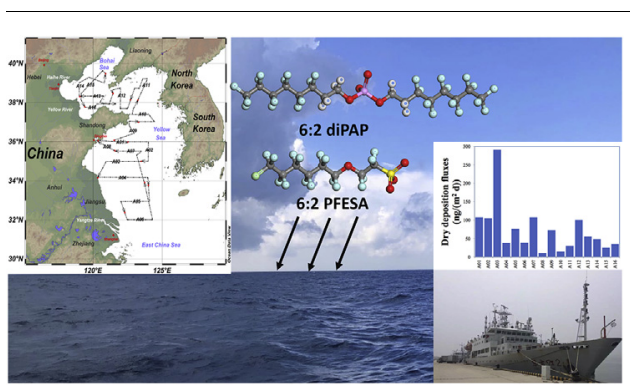

A R T I C L E I N F O

\section{Keywords:}

PFAS

Gas/particle distribution

Dry deposition

Marine air

\begin{abstract}
A B S T R A C T
A total of 26 alternative and legacy perfluoroalkyl and polyfluoroalkyl substances (PFASs) were investigated in air collected above the Bohai and Yellow Seas during a research cruise between June 28 and July $15,2016$. $\Sigma$ PFAS concentrations ranged from $70 \mathrm{pg} \mathrm{m}^{-3}$ to $430 \mathrm{pg} \mathrm{m}^{-3}$ (mean $230 \pm 100 \mathrm{pg} \mathrm{m}^{-3}$ ). Trifluoroacetic acid (TFA, mean $120 \pm 80 \mathrm{pg} \mathrm{m}^{-3}$ ) and $8: 2$ fluorotelomer alcohol $\left(8: 2 \mathrm{FTOH}\right.$, mean $\left.34 \pm 46 \mathrm{pg} \mathrm{m}^{-3}\right)$ were the predominating compounds of ionizable PFASs (i-PFASs) and neutral PFASs (n-PFASs), respectively. The contributions of $\mathrm{C}_{4}$ and $\mathrm{C}_{6}$ i-PFASs were higher than those of $\mathrm{C}_{8}$ i-PFASs. Alternative substances, such as chlorinated 6:2 polyfluoroalkyl ether sulfonic acids (Cl-6:2 PFESA, mean $1.6 \pm 1.2 \mathrm{pg} \mathrm{m}^{-3}$ ) and diPAPs (mean $1.6 \pm 1.3 \mathrm{pg} \mathrm{m}^{-3}$ ), were only detected on the filter. The distribution coefficient of 10:2 FTOH was higher than 8:2 FTOH, which could be explained by the length of the carbon chain. The gas phase dry deposition velocities were simulated, and the values ranged from $0.08 \pm 0.12 \mathrm{~cm} \mathrm{~s}^{-1}$ to $0.85 \pm 0.28 \mathrm{~cm} \mathrm{~s}^{-1}$. For i-PFASs and diPAPs, the estimated fluxes of the particle phase were higher than those of the gas phase. For n-PFASs and TFA, the gas phase deposition played a key role. The $\Sigma$ PFASs dry deposition fluxes were $11-290 \mathrm{ng}^{\left(\mathrm{m}^{2} \mathrm{~d}\right)^{-1}(\mathrm{mean}}$ $\left.72 \pm 67 \mathrm{ng}\left(\mathrm{m}^{2} \mathrm{~d}\right)^{-1}\right)$. The measurement of the concentrations in the gas and particle phases simultaneously provided a more comprehensive understanding of PFAS behaviours in air.
\end{abstract}

\footnotetext{
* Corresponding author. MOE Key Laboratory of Pollution Processes and Environment Criteria, College of Environmental Science and Engineering, Nankai University, Tianjin, 300350, China.

E-mail address: zhaozhen@nankai.edu.cn (Z. Zhao).

1 The first two authors contributed equally to this work.
} 


\section{Introduction}

Perfluoroalkyl and polyfluoroalkyl substances are anthropogenic substances with a fluorocarbon moiety $\mathrm{C}_{\mathrm{n}} \mathrm{F}_{2 \mathrm{n}+1}^{-}$(Buck et al., 2011). These substances have been widely used for more than 60 years in industrial and household applications, including textile coatings, metal plating, paper treatments, and fire-fighting foams (Ahrens et al., 2012; Deng et al., 2018). Some PFASs are thermally and chemically stable and can be transported long distances through air and water; they have also been detected in worldwide coastal and marine environments (Ahrens et al., 2011a; Benskin et al., 2012; Heydebreck et al., 2015; Wang et al., 2015a). Ionizable PFASs (i-PFASs), such as perfluoroalkyl carboxylic acids (PFCAs) and perfluoroalkane sulfonic acids (PFSAs), are strong acids and are mainly distributed in water and particles (Benskin et al., 2012; Ge et al., 2017), whereas most neutral PFASs (n-PFASs), such as fluorotelomer alcohols (FTOHs), perfluorooctane sulfonamides (FOSAs), and perfluorooctane sulfonamidoethanols (FOSEs), are volatile and are mainly distributed in air (Li et al., 2011; Shoeib et al., 2010). Because of their (bio)degradation, n-PFASs are considered indirect sources of i-PFASs (Dassuncao et al., 2017; Ellis et al., 2004; Martin et al., 2006). Due to their toxicity and potential threat to ecosystems and human health (Giesy et al., 2010; Mahapatra et al., 2017; Trasande et al., 2017), the manufacture and application of 8-carbon groups $\left(\mathrm{C}_{8}\right)$, such as perfluorooctane sulfonic acid (PFOS) and their related compounds, have been regulated worldwide (UNEP, 2017a; b). After the phase-out of $\mathrm{C}_{8}$ homologues, shorter-chained substitutes, such as perfluorobutanoic acid (PFBA) and perfluorobutane sulfonate acid (PFBS) (Moeller et al., 2010), as well as other alternatives, such as chlorinated polyfluorinated ether sulfonate (Cl-PFAES) (Deng et al., 2018) and 3H-perfluoro-3-[(3-methoxy-propoxy) propanoic acid (ADONA) (Fromme et al., 2017), are more concerning because of their occurrence in the environment and in biota. Trifluoroacetic acid (TFA) has the shortest carbon length and was detected at high levels in wet deposition and aquatic systems, while the distribution in aerosols has been less frequently investigated (Hu et al., 2013; Wu et al., 2014). Additionally, polyfluoroalkyl phosphoric acid diesters (diPAPs), which are used in food paper packaging, have been widely detected in indoor dust and human serum (D'Eon et al., 2009; Eriksson and Karrman, 2015), and they were considered possible precursors of i-PFASs (D'Eon and Mabury, 2007, 2011; Lee et al., 2010).

The gas/particle distribution and the dry deposition influenced the distribution and transport of PFASs in the atmospheric environment. Although the high volume air sampler results in bias in the determination of partition coefficients (Ahrens et al., 2012; Arp et al., 2008), it is still quite popular in PFAS studies (Bossi et al., 2016) (Wong et al., 2018), and as Wang et al. (2014b) reported, no significant differences were found between the measured and the corrected coefficients for $\mathrm{n}$ PFASs. The $K p$ values increased with the increasing relative humidity in the air, which suggested the strong partitioning potential of the particle phase in marine atmospheres (Arp et al., 2008). However, fewer studies in marine air than land and coastal city air have been conducted (Ahrens et al., 2012; Shoeib et al., 2004; Yao et al., 2017b). The dry deposition was an important path for PFAS transport from air to surface water, while the estimation of fluxes based on field investigation have been rare.

The Bohai Sea is a semi-closed sea that receives large amount of PFASs from adjacent rivers because of the development of fluorotelomer industries in coastal cities (Chen et al., 2017a; Wang et al., 2014a). The Yellow Sea receives contaminates not only from Chinese mainland but also from the Korean Peninsula. Previous studies reported the manufacture and release of PFASs in surrounding countries and their ubiquitous occurrence in aquatic systems (Chen et al., 2017c; Lam et al., 2014; Xie et al., 2013a, 2013b). One previous study conducted by the same group investigated the n-PFASs in the gas phase (Zhao et al., 2017), but comprehensive investigation of i-PFASs and n-PFASs in air above the two seas are lacking, and the dry deposition fluxes to the surface water are unknown.

The aims of this study were i) to investigate the distribution and sources of alternative and legacy PFASs in air above the Bohai and Yellow Seas, and ii) to estimate the distribution coefficients of $\mathrm{i}$ - and nPFASs in marine air and to simulate the dry deposition.

\section{Materials and methods}

\subsection{Sampling collection}

Air samples were taken from the front of the upper deck $(15 \mathrm{~m}$ above sea level) of the China research vessel Dongfanghong 2 in the Bohai and Yellow Seas $\left(32-39.65^{\circ} \mathrm{N}, 119-124^{\circ} \mathrm{E}\right)$ from June 28 to July 16, 2016 (Figure S1). Sixteen samples ( $\sim 350 \mathrm{~m}^{3}$ per sample, $24 \mathrm{~h}$ ) were taken using a high-volume air sampler equipped with a glass fibre filter ( $[\mathrm{GFF}], \mathrm{GF} / \mathrm{F}$, pore size: $0.7 \mu \mathrm{m}$ ) to trap the particle phase and a selfpacked PUF/XAD-2 glass column (PUF: $5.0 \mathrm{~cm} \times 2.5 \mathrm{~cm}$; $35 \mathrm{~g}$ XAD-2, particle size: $0.3-1.0 \mathrm{~mm}$ ) for the gas phase (Xie et al., 2013c). Johansson et al. suggested that a layer of humidity could scavenge gaseous i-PFASs from the filters. During this campaign, the relative humidity of the air ranged from $76.2 \%$ to $97.3 \%$, and a layer of water formed very quickly once the sampling started. The air columns and filters were stored at $-20^{\circ} \mathrm{C}$ until analysis. The sampling parameters, including date, position, air and surface water temperature, and wind direction and speed, are listed in Table S1.

\subsection{Standards and chemicals}

The information on the standards used in this study is presented in Table S2. The native standards included 17 i-PFASs, C2-C12PFCAs, C4, C6 and C8 PFSAs, Cl-6:2 and Cl-8:2 PFESA, ADONA and HFPO-DA, 7 nPFASs, 6:2, 8:2 and 10:2 FTOH, Me- and Et-FOSA, Me- and Et-FOSE, and 2 diPAPs, 6:2 and 8:2 diPAP. Twelve mass-labelled standards for quantification were used as the internal standards (ISs): ${ }^{13} \mathrm{C}$-labelled C2-, C4-, C8-PFCAs, C8-PFSAs and 2,3,3,3-tetrafluoro-2-(1,1,2,2,3,3,3heptafluoropropoxy) propanoic acid (HFPO-DA), ${ }^{18}$ O-labelled C6PFSAs, ${ }^{1} \mathrm{H}$ - and ${ }^{13} \mathrm{C}$-labelled 6:2 and 8:2 FTOH, ${ }^{13} \mathrm{C}$-labelled N-EtFOSA, N-EtFOSE, and ${ }^{13} \mathrm{C}$-labelled 6:2 and 8:2 diPAP. ${ }^{13} \mathrm{C}$-labelled 8:2 FTUCA and 7:1 FTOH were employed as the injection standards (InjSs). All the standards were purchased from Wellington Laboratories (Ontario, Canada). Methanol, acetone, dichloromethane (DCM), and $n$-hexane were all residue grade. Methanol was purchased from Merck (Darmstadt, Germany), and acetone, dichloromethane (DCM), and $n$-hexane were purchased from CNW (Kolner, Germany). Ammonium hydroxide $\left(\mathrm{NH}_{4} \mathrm{OH}\right)(25 \%)$ was purchased from Aladdin (Kolner, Germany). Ultrapure Millipore water was produced by a Milli- $Q^{\circ}$ Plus 185 system (Zug, Germany), and the details of the analytical method could be found elsewhere (Tian et al., 2018).

\subsection{Extraction and analysis}

The pretreatment of the samples has been described elsewhere (Wang et al., 2014b; Yao et al., 2017a). Briefly, the air columns were Soxhlet-extracted by DCM for $24 \mathrm{~h}$ after being spiked with $10 \mathrm{ng}$

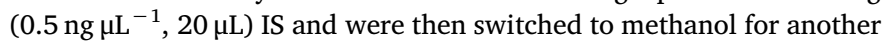
$24 \mathrm{~h}$ to collect possible residue. For the filter samples, the filter was cut in half. One half was used for Soxhlet extraction with DCM for $24 \mathrm{~h}$, and the other half was ultrasonically extracted three times with $15 \mathrm{~mL}$ methanol. All the extracts were concentrated with rotary evaporation to approximately $2 \mathrm{~mL}$. The extracts were further concentrated to $200 \mu \mathrm{L}$ under a gentle stream of high purity nitrogen (> 99.99\%) after being transferred to the keeper solvent (methanol for i-PFASs and diPAPs and $n$-hexane for n-PFASs). Before instrument analysis, the samples were spiked with InjS.

For i-PFASs and diPAPs, quantification was performed by a highperformance liquid chromatography-tandem mass spectrometry system 
(HPLC-MS/MS) with an Agilent1260 liquid chromatography and an Agilent 6460 mass spectrometer and operated in electrospray negative ionization (ESNI) multiple-reaction monitoring (MRM) mode. For nPFASs, quantification was performed by an Agilent 7890B gas chromatograph coupled with an Agilent 5977B mass spectrometer (GC-MS) in selective ion monitoring (SIM) mode with chemical ionization (CI) using methane as the reagent gas. The details of instrumental analysis are provided in Text $\mathrm{S} 1$.

\subsection{Quality assurance and quality control}

Before sampling, all the air columns were pre-cleaned by Soxhlet extraction with methanol, DCM and n-hexane for $24 \mathrm{~h}$. GFFs were heated at $450{ }^{\circ} \mathrm{C}$ for $12 \mathrm{~h}$ prior to use. All the materials which may contact our sample were repleaced with PP or glass. To avoid degradation of the target compounds, the air columns were protected against sunlight. Two field blanks and three procedure blanks were prepared. PFOA and PFOS were found in the blank samples, which had average concentrations of $0.085 \pm 0.034 \mathrm{pg} \mathrm{m}^{-3}$ and $0.11 \pm 0.014 \mathrm{pg} \mathrm{m}^{-3}$, respectively. The instrumental detection limit (IDL) was defined using a signal-to-noise ratio of 3 . Method quantification limits (MQLs) for analytes detectable in blanks were derived from three times the standard deviation plus the mean value in blanks. For the analytes not detectable in blanks, a signal-to-noise ratio of 10 was used as the MQL. The IDLs and MQLs for the individual compounds are presented in Table S3. Average recoveries of mass-labelled standards were between $60 \pm 12 \%\left({ }^{13} \mathrm{C}_{4}\right.$-PFOA) and $100 \pm 19 \%\left({ }^{13} \mathrm{C}_{2}-6: 2\right.$ diPAP) (Table S4). Concentrations were not modified by IS recoveries.

\subsection{Air mass back-trajectories}

Five-day air mass back trajectories (BTs) were calculated for each air sample in $6 \mathrm{~h}$ steps by NOAA's HYSPLIT model (Draxler and Hess, 1997). The sampling height was set at $10 \mathrm{~m}$ above sea level.

\subsection{Gas/particle distribution}

The measured particle phase fraction $\varphi$ was determined by the following equation:

$\varphi=\frac{C_{p}}{C_{p}+C_{g}}$

Here, $C_{p}$ and $C_{g}$ were the measured concentrations of PFASs in particle and gas phases $\left(\mathrm{pg} \cdot \mathrm{m}^{-3}\right)$, respectively.

The experimental organic matter normalized distribution coefficient between gas and particle phases, $K_{p}$, was described by the following equation (Pankow and Bidleman, 1991; Yamasaki et al., 1982):

$\mathrm{K}_{\mathrm{p}}=\frac{\mathrm{C}_{\mathrm{p}} / \mathrm{C}_{\mathrm{TSP}}}{\mathrm{C}_{\mathrm{g}}}$

Here, $C_{T S P}$ was the total suspended particle concentration $\left(\mu \mathrm{g} \cdot \mathrm{m}^{-3}\right)$. Parallel samples were taken on the same cruise, and the data were reported by Li et al. (2018).

\subsection{Calculation of gas and particle phase dry deposition}

The details of the simulation of the gas phase deposition velocity were described by our previous study (Zhao et al., 2017). Modifications were used in this study. Briefly, velocities at heights of $1.5 \mathrm{~m}, 3.9 \mathrm{~m}$ and $10 \mathrm{~m}$ were estimated. Contaminants near the water layer had the faster deposition velocities. The velocities were calculated every five hours using meteorological parameters of temperature, pressure, wind direction and wind speed. To estimate the flux of gas deposition, mean velocities were used. The particle phase dry deposition velocity was suggested to be $0.2 \mathrm{~cm} \mathrm{~s}^{-1}$ in coastal and marine air (Wang et al.,

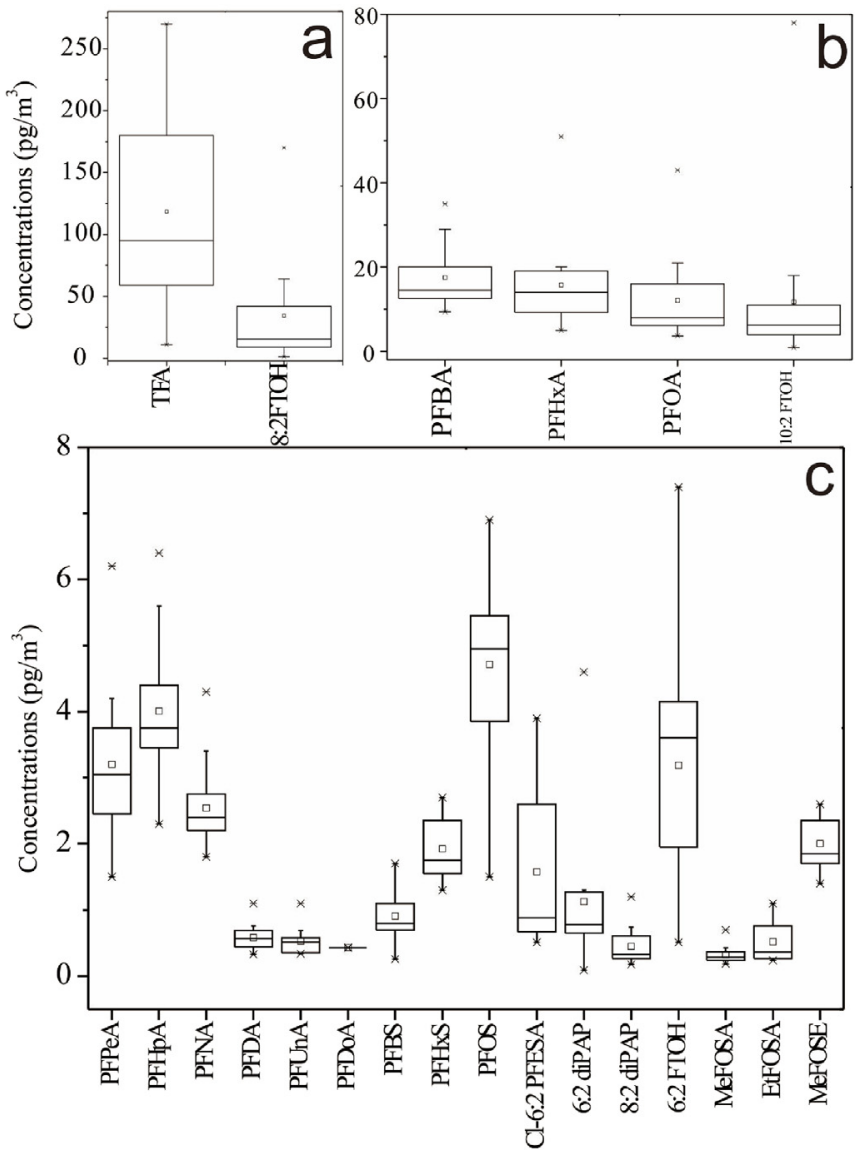

Fig. 1. Concentrations (pg.m ${ }^{-3}$ ) of PFASs in the air above the Bohai and Yellow Seas. a: 8:2 FTOH and TFA, b: 10:2 FTOH, PFBA, PFHxA and PFOA, and c: other homologues detected in samples.

2015b). The deposition fluxes could be calculated by the following equation:

$F_{\text {dry }}=C_{\mathrm{g}} v_{\mathrm{g}}+C_{\mathrm{p}} v_{\mathrm{p}}$

Here, $C_{g}$ and $C_{p}$ were the concentrations in gas and particle phases, respectively. $v_{g}$ and $v_{p}$ were the deposition velocities for gas and particle phases, respectively.

\section{Results and discussion}

\subsection{Concentrations, composition and sources of PFASs in air}

Concentrations of PFASs are presented in Fig. 1 and Table S5-11. $\mathrm{C}_{2}$, $\mathrm{C}_{4}-\mathrm{C}_{10}$ PFCAs and $\mathrm{C}_{6}$ and $\mathrm{C}_{8}$ PFSAs were detected in the gas phase. More i-PFAS homologues were found in the particle phase, such as $\mathrm{C}_{11}-\mathrm{C}_{12}$ PFCAs, $\mathrm{C}_{4}$ PFSAs and Cl-6:2 PFESA. The concentrations of TFA were two to three orders of magnitude higher than other individual i-PFASs ranging from 11 to $270 \mathrm{pg} \mathrm{m}^{-3}$ (mean $120 \pm 80 \mathrm{pg} \mathrm{m}^{-3}$ ). Excluding TFA, the concentrations of $\Sigma$ i-PFASs ranged from $36 \mathrm{pg} \mathrm{m}^{-3}$ to $110 \mathrm{pg} \mathrm{m}^{-3}$ (mean $64 \pm 22 \mathrm{pg} \mathrm{m}^{-3}$ ). PFBA and PFHxA were the predominating compounds with concentrations ranging from $9.4 \mathrm{pg} \mathrm{m}^{-3}$ to $35 \mathrm{pg} \mathrm{m}^{-3}$ (mean $18 \pm 6.9 \mathrm{pg} \mathrm{m}^{-3}$ ) and from $4.9 \mathrm{pg} \mathrm{m}^{-3}$ to $51 \mathrm{pg} \mathrm{m}^{-3}$ (mean $16 \pm 11 \mathrm{pg} \mathrm{m}^{-3}$ ), respectively. One alternative homologue of PFOS (Deng et al., 2018), Cl-6:2 PFESA, was detected in the particle phase with concentrations ranging from $<0.04 \mathrm{pg} \mathrm{m}^{-3}$ to $3.9 \mathrm{pg} \mathrm{m}^{-3}$, which was significantly lower than that detected in Dalian City (722 $\mathrm{pg} \mathrm{m}^{-3}$ in 2014) (Zhao et al., 2017). The 6:2 and 8:2 diPAPs were detected in the particle phase with $\Sigma$ diPAPs concentrations ranging from < MQL to $5.3 \mathrm{pg} \mathrm{m}^{-3}$ (mean $1.6 \pm 1.3 \mathrm{pg} \mathrm{m}^{-3}$ ). Six n-PFASs 

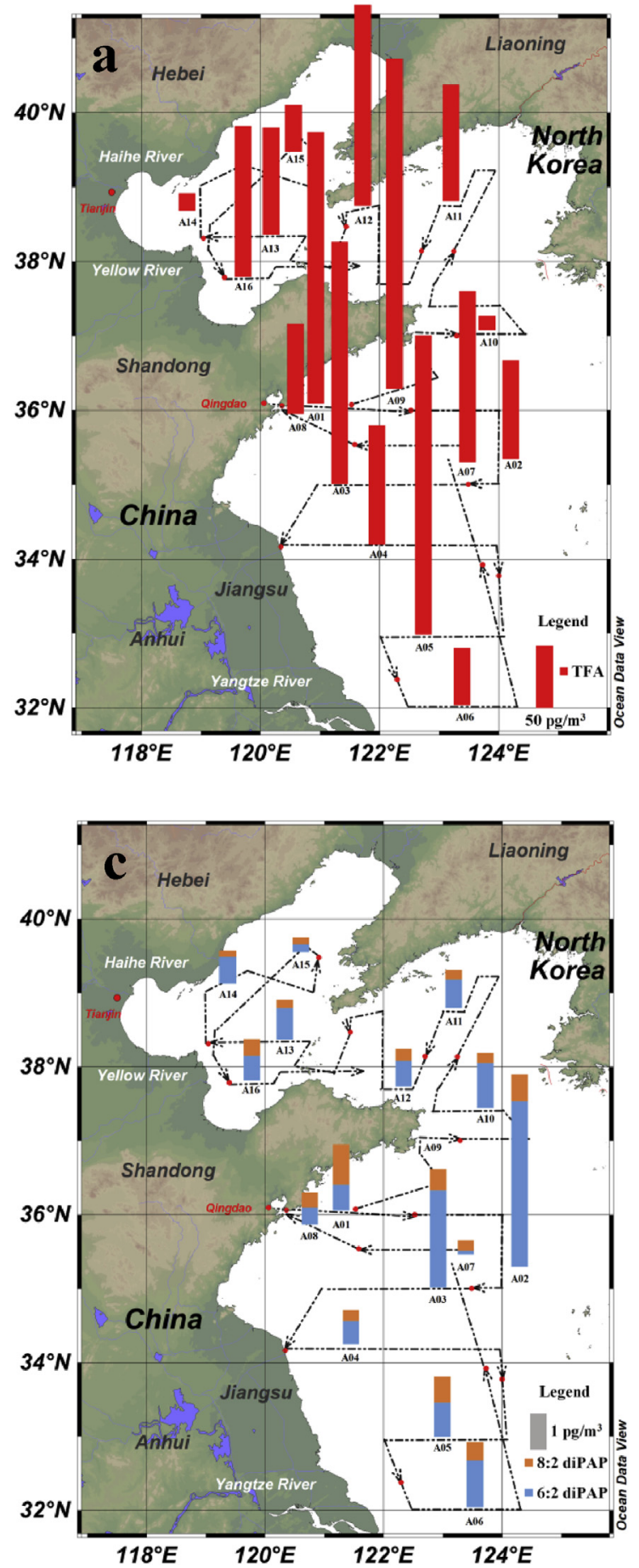
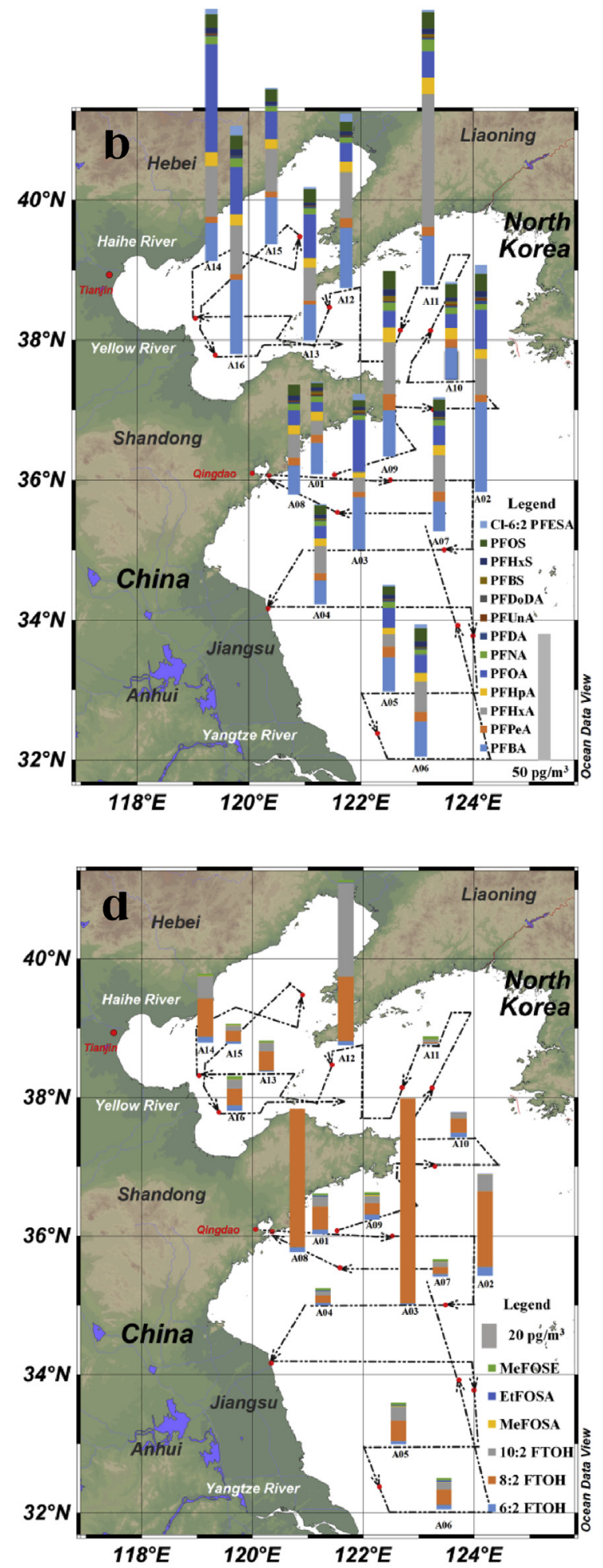

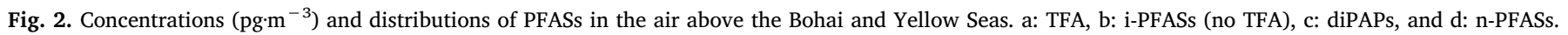

were quantified in the gas phase: 6:2, 8:2 and 10:2 FTOH, MeFOSA, EtFOSA and MeFOSE. Three homologues were quantified in particle phase: 8:2 and 10:2 FTOH and EtFOSE. The concentrations of $\Sigma$ n-PFASs ranged from $6.8 \mathrm{pg} \mathrm{m}^{-3}$ to $170 \mathrm{pg} \mathrm{m}^{-3}$ (mean $51 \pm 50 \mathrm{pg} \mathrm{m}^{-3}$ ). The 8:2 and 10:2 FTOH were the predominant compounds with concentrations ranging from $1.3 \mathrm{pg} \mathrm{m}^{-3}$ to $170 \mathrm{pg} \mathrm{m}^{-3}$ (mean $34 \pm 46 \mathrm{pg} \mathrm{m}^{-3}$ ) and $<0.42 \mathrm{pg} \mathrm{m}^{-3}$ to $78 \mathrm{pg} \mathrm{m}^{-3}$ (mean $12 \pm 19 \mathrm{pg} \mathrm{m}^{-3}$ ), respectively.

The composition of i-PFASs (excluding TFA) is presented in Figure
S2. The contributions of short-chain i-PFASs, such as PFBA $(29 \% \pm 7 \%)$ and PFHxA (22\% \pm 9\%), were higher than C8 i-PFASs, such as PFOA $(18 \pm 9 \%)$ and PFOS $(8 \% \pm 3 \%)$, indicating a shift towards use of short-chained PFASs. The ratios of PFCA homologues were suggested to be markers for degradation of FTOHs (Young et al., 2007). The ratios of PFDA to PFUnDA $(1.1 \pm 0.4)$ were close to the indirect source $(0.9 \pm 0.8)$, suggesting the degradation of 10:2 FTOH in the air (Young et al., 2007). The ratio of PFOA to PFNA was $4.5 \pm 3.4$, which was higher than the indirect source $(1.5 \pm 0.8)$ 
(Ellis et al., 2004; Young et al., 2007). Chen et al. investigated the iPFAS concentrations in Bohai coastal water. The ratio of PFOA to PFNA was over 100, and direct release was considered the main source (Chen et al., 2017b). i-PFASs in coastal and marine surface waters could transport to air as aerosols and then undergo long-range atmospheric transport, which was identified as the direct source (Ahrens et al., 2011b; Prevedouros et al., 2006; Yao et al., 2017b). The significantly lower ratios of PFOA to PFNA in air compared to coastal water suggested the moderate contribution of direct sources. As the major ingredient of F-53B used for metal plating industries, Cl-6:2 PFESA was detected to have a low contribution of $2 \% \pm 1 \%$ of $\Sigma$ PFASs, which was lower than PFOS $(8 \% \pm 3 \%)$. Liu et al. (2017) reported a larger contribution of Cl-6:2 PFESA (37-95\%) than PFOS in Dalian, China, which had a converse composition pattern. The degradation of Cl-6:2 PFESA to hydrogen-substituted PFESAs has been reported in anaerobic conditions (Lin et al., 2017). More studies should be conducted to illustrate the possible degradation in air and during transport. As PFOA alternative substances, HFPO-DA and ADONA could not be quantified in air samples. High concentrations of HFPO-DA have been detected in rivers and Bohai coastal water (Heydebreck et al., 2015), and the migration between the air and water requires further investigation. The major sources of TFA in the environment were the degradation of ozone-depleting substances (ODS), such as hydrochlorofluorocarbons (HCFCs) (Metz et al., 2000; Russell et al., 2012). The thermolysis of perfluorinated polymers was a possible source that has received more attention because of concern over PFASs (Ellis et al., 2001).

The composition of n-PFASs is presented in Figure S3. Concentrations of 8:2 FTOH and 10:2 FTOH accounted for 19\%-99\% and $16 \%-57 \%$ (excluding one sample below the MQL) of $\Sigma$ n-PFASs concentrations, respectively, which was consistent with a study conducted in 2012 (Zhao et al., 2017). Concentrations of $\Sigma F T O H s$ (48 $\pm 50 \mathrm{pg} \mathrm{m}^{-3}$ ) were one to two orders of magnitude higher than $\Sigma$ FOSAs $\left(0.61 \pm 0.48 \mathrm{pg} \mathrm{m}^{-3}\right)$ and $\Sigma$ FOSEs $\left(1.5 \pm 0.93 \mathrm{pg} \mathrm{m}^{-3}\right)$. The fingerprint ratios of $6: 2$ to $8: 2 \mathrm{FTOH}$ and $10: 2$ to $8: 2$ FTOH were $0.01-0.41$ and 0 to 1.69 , respectively, which were different from the study conducted in 2012 (6:2 to 8:2 FTOH: 0.01 to 0.04 and 10:2 to 8:2 FTOH: 0.08 to 0.33 ), suggesting a change in usage (Zhao et al., 2017). The ratios for commercial fluorotelomer products were 0.02 (6:2 to 8:2 FTOH) and 0.6 (10:2 to 8:2 FTOH), and for lubricants, the rations were 0.98 and 0.74 , respectively (Li et al., 2011). The large range of substance ratios suggested complex sources and their use in various commercial products. diPAPs have been widely detected in dust because of their affinity for particles, which was consistent with this study (De Silva et al., 2012; Eriksson and Karrman, 2015). diPAPs were possible precursors of FTOHs and PFCAs (Lee et al., 2010; Liu and Liu, 2016). In this study, concentrations of $6: 2$ diPAPs $\left(1.1 \pm 1.1 \mathrm{pg} \mathrm{m}^{-3}\right)$ were at comparable levels with 6:2 FTOH $\left(3.2 \pm 1.7 \mathrm{pg} \mathrm{m}^{-3}\right)$, and concentrations of $8: 2$ diPAPs $\left(0.45 \pm 0.27 \mathrm{pg} \mathrm{m}^{-3}\right)$ were significantly lower than 8:2 FTOH $\left(34 \pm 46 \mathrm{pg} \mathrm{m}^{-3}\right)$, which indicated moderate release from food packaging and personal care products (Begley et al., 2008).

\subsection{Distribution of PFASs and air mass origination}

The spatial distribution of the $\Sigma$ PFASs concentrations are presented in Fig. 2. The results of air mass BTs of individual air samples are provided in Figure S6. High concentrations were found in A03 $\left(430 \mathrm{pg} \mathrm{m}^{-3}\right), \quad$ A05 $\left(305 \mathrm{pg} \mathrm{m}^{-3}\right), \quad$ A09 $\left(362 \mathrm{pg} \mathrm{m}^{-3}\right)$ and A12 $\left(370 \mathrm{pg} \mathrm{m}^{-3}\right)$, which were all distributed in Yellow Sea. For different groups of PFASs, the distributions were different. The highest concentrations of TFA were found in A05 $\left(240 \mathrm{pg} \mathrm{m}^{-3}\right)$, for which air mass was the land source, and A09 $\left(270 \mathrm{pg} \mathrm{m}^{-3}\right)$, for which air mass was mainly from the Yellow Sea (Fig. 2a). On the mainland, especially the cities, the precursor concentrations were higher than in remote areas (Chan et al., 2006), which could result in the high concentration of ODS products. While transporting to the coast and sea, TFAs were generated and deposited along the way (Antinolo et al., 2017; Jimenez et al.,
2016). On the coast, the high concentrations of hydroxyl radicals possibly enhanced the photochemical transformation of precursors and then elevated the TFA levels (Mopper and Zhou, 1990). For $\Sigma$ i-PFASs (excluding TFA), high concentrations were found in the Bohai Sea (A14:100 $\mathrm{pg} \mathrm{m}^{-3}$ and A16: $90 \mathrm{pg} \mathrm{m}^{-3}$ ) and the Yellow Sea (Fig. 2b). The air mass of A14 mainly originated from the Bohai coast where fluorotelomer industrial parks are located (Heydebreck et al., 2015), and for A16, the air mass went through another hot spot in Liaoning Province (Bao et al., 2017). Different from other PFAS homologues, high concentrations of diPAPs were mainly distributed far away from the Chinese mainland (A02:5.3 $\mathrm{pg} \mathrm{m}^{-3}$ and $\mathrm{A} 03: 3.3 \mathrm{pg} \mathrm{m}^{-3}$ ), and the air mass mainly originated from the southeast part of China and went through the coast of Zhejiang Province (Fig. 2c). The highest concentration of $\Sigma$ n-PFASs (excluding TFA) was found in A03 $\left(170 \mathrm{pg} \mathrm{m}^{-3}\right)$ in the Southern Yellow Sea, and the air mass was mainly from Pearl River Delta and transported through the central part of southeast China, which was different from other samples (Fig. 2d) (Liu et al., 2015a).

\subsection{Gas/particle distribution of PFASs}

TFA was an ionizable homologue $\left(p K_{a}=0.23\right)$ mainly distributed in the gas phase. The particle phase fraction $\varphi$ values of TFA varied over a large range from 0 to $100 \%$ (mean $27 \% \pm 32 \%$ ), which was consistent with coastal cities and one inland city in China (Hu et al., 2013; Yao et al., 2016, 2017a). The factors that influence TFA distribution were complex. On one hand, the high vapor pressure (13 kPa) makes it tend to partition in the gas phase (Draxler and Hess, 1997). On the other hand, the high humidity over the seas (76.2-97.3\%) makes it distribute in the aqueous film of particles due to its low $p K_{a}$ value (Wang et al., 2014b).

The $\varphi$ values of n-PFASs in the Bohai and Yellow Seas were calculated for 8:2 and 10:2 FTOH in 8 samples because of the low detection frequency and high MQLs in the particle phase. The $\varphi$ values for 10:2 FTOH $(7 \% \pm 1 \%)$ were higher than $8: 2$ FTOH $(3 \% \pm 2 \%)$, which was consistent with a coastal site in Germany (Wang et al., 2014b). The measured $\log \mathrm{K} p$ values were $-3.4 \pm 0.4$ for 8:2 FTOH (5 samples) and $-2.3 \pm 0.8$ for $10: 2$ FTOH ( 2 samples), respectively, which had an increasing trend with the longer carbon chain (Yuan et al., 2016). The $\log \mathrm{Kp}$ values of 8:2 FTOH in the air over the Bohai and Yellow Seas $(-3.4 \pm 0.4)$ were lower than the coastal city in Germany $(-3.1)$ and a site in Canada, which was partly because of the higher temperature on this cruise $\left(23.3 \pm 0.60^{\circ} \mathrm{C}\right)$ than previous studies $\left(10.4^{\circ} \mathrm{C}\right.$ for German site and $-9.4-7.7^{\circ} \mathrm{C}$ for Canadian site) (Ahrens et al., 2012; Yuan et al., 2016).

\subsection{Comparison with worldwide PFASs concentrations in air}

The comparison of PFAS concentrations in previous studies is shown in Table S12. TFA concentrations $\left(120 \pm 80 \mathrm{pg} \mathrm{m}^{-3}\right)$ in the air above the Bohai and Yellow Seas were significantly lower than those in Beijing, China $\left(1580 \pm 558 \mathrm{pg} \mathrm{m}^{-3}\right.$ ) (Hu et al., 2013) and Toronto, Canada (760 $\mathrm{pg} \mathrm{m}^{-3}$ ) (Liu et al., 2015a) which could indicate the levels in cities. The concentrations of $\Sigma$ PFCAs and SAs in the air above the Bohai and Yellow Seas $\left(48-110 \mathrm{pg} \mathrm{m}^{-3}\right.$ ) were lower than those of the coastal cities of the Bohai Sea (mean $151 \mathrm{pg} \mathrm{m}^{-3}$ ) (Pankow and Bidleman, 1991), suggesting deposition during transport. PFOA concentrations $\left(3.7-43 \mathrm{pg} \mathrm{m}^{-3}\right.$ ) were at the same levels as a weast water treatment plant $\left(2.99-47.3 \mathrm{pg} \mathrm{m}^{-3}\right)$ and landfills $\left(<0.04-46.2 \mathrm{pg} \mathrm{m}^{-3}\right)$ in Canada (Yamasaki et al., 1982), but higher than in Shenzhen, China (1.5-15 $\mathrm{pg} \mathrm{m}^{-3}$ ) (Liu et al., 2015b) and some European cities, such as Zurich, Switzerland $\left(7.7 \mathrm{pg} \mathrm{m}^{-3}\right.$ ) (Muller et al., 2012), Kejeller, Norway $\left(1.54 \mathrm{pg} \mathrm{m}^{-3}\right)$ and Manchester, UK (15.7 $\mathrm{pg} \mathrm{m}^{-3}$ ) (Barber et al., 2007), which suggested that PFOA pollution should be highly concerning for the future. For PFOSs, the concentrations $\left(1.5-6.9 \mathrm{pg} \mathrm{m}^{-3}\right)$ were lower than a source region in Tianjin, China (3.20-171 $\mathrm{pg} \mathrm{m}^{-3}$ ) (Yao et al., 2016) and a WWTP in 
Canada (3.05-171 $\mathrm{pg} \mathrm{m}^{-3}$ ) (Yamasaki et al., 1982), while they were comparable with European cities $\left(1-2.3 \mathrm{pg} \mathrm{m}^{-3}\right.$ for Zurich, Switzerland, Kejeller, Norway and Manchester, UK) (Barber et al., 2007; Muller et al., 2012). As the substitutes of $C_{8}$ PFASs, PFBA concentrations in the air above the Bohai and Yellow Seas (9.4-35 p pg.m ${ }^{-3}$ ) were comparable to coastal cities (3.07-91.2 $\mathrm{pg} \mathrm{m}^{-3}$ in summer), while PFBS concentrations in marine air $\left(0.26-1.7 \mathrm{pg} \mathrm{m}^{-3}\right)$ were lower than coastal cities (37.7-110 $\mathrm{pg} \mathrm{m}^{-3}$ in summer) (Pankow and Bidleman, 1991).

Compared with the data from 2012, which was obtained by the same method targeting a similar area, the $\Sigma$ FTOHs concentrations (3.9-170 $\left.\mathrm{pg} \mathrm{m}^{-3}\right)$ were lower than those in $2012\left(73-543 \mathrm{pg} \mathrm{m}^{-3}\right)$ suggesting a decreasing volume of manufacture and usage (Zhao et al., 2017). Comparable concentrations were reported in the Gulf of Mexico and East Coast of the USA (5.46-156 $\mathrm{pg} \mathrm{m}^{-3}$ ) (Shoeib et al., 2010), Büsum, German coast (7.3-146 $\mathrm{pg} \mathrm{m}^{-3}$ ) (Wang et al., 2014b) and North Sea (37-127 $\mathrm{pg} \mathrm{m}^{-3}$ ) (Xie et al., 2013c) where FTOHs mainly originated from land-based sources, and in the Beaufort Sea (39-138 $\mathrm{pg} \mathrm{m}^{-3}$ ), Hudson Bay (44-129 $\mathrm{pg} \mathrm{m}^{-3}$ ), and Canadian Arctic (Ahrens et al., 2011a) where levels were highly influenced by the Arctic air mass. Concentrations of $\Sigma$ FTOHs (3.9-170 $\mathrm{pg} \mathrm{m}^{-3}$ ) were lower than Asian (51.4-1210 $\mathrm{pg} \mathrm{m}^{-3}$ ) (Li et al., 2011) and European cities (50-789 $\mathrm{pg} \mathrm{m}^{-3}$ ) (Barber et al., 2007; Jahnke et al., 2007; Muller et al., 2012) and higher than in background areas (nd- $49.9 \mathrm{pg} \mathrm{m}^{-3}$ ) (Shoeib et al., 2010) and open oceans (2.49-67.12 $\mathrm{pg} \mathrm{m}^{-3}$ ) (Wang et al., 2015a). For $\Sigma F$ FOSAs and $\Sigma F$ FOSEs, the concentrations in the air above the Bohai and Yellow Seas $\left(0.28-1.2 \mathrm{pg} \mathrm{m}^{-3}\right.$ for $\Sigma$ FOSAs and $1.4-2.6 \mathrm{pg} \mathrm{m}^{-3}$ for $\Sigma$ FOSEs) were comparable to the data from 2012 (1.3-11 $\mathrm{pg} \mathrm{m}^{-3}$ for $\Sigma$ FOSAs and $<0.10-0.27 \mathrm{pg} \mathrm{m}^{-3}$ for $\Sigma$ FOSEs) (Zhao et al., 2017) and the Atlantic Ocean $\left(0.10-1.38 \mathrm{pg} \mathrm{m}^{-3}\right.$ for $\Sigma$ FOSAs and $0.05-2.00 \mathrm{pg} \mathrm{m}^{-3}$ for $\Sigma$ FOSEs) (Wang et al., 2015a). Higher concentrations of $\Sigma$ FOSEs were detected than those of $\Sigma$ FOSAs in previous studies, while the same pattern was not found in Bohai and Yellow Sea air.

\subsection{Dry deposition of PFASs in surface water}

Considering the sampling height, the $10 \mathrm{~m}$ gas phase deposition velocities were used to discuss PFAS deposition (Table S13). The velocities varied from $0.08 \pm 0.12 \mathrm{~cm} \mathrm{~s}^{-1}$ (A08) to $0.85 \pm 0.28 \mathrm{~cm} \mathrm{~s}^{-1}$ (A03). The dry deposition fluxes of individual PFASs are presented in Table 1 and Table S14-S20. For TFA, the deposition fluxes ranged from

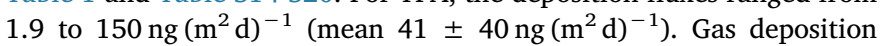
played a key role accounting for $77 \% \pm 67 \%$ of total fluxes. For other

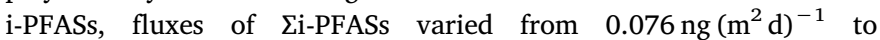
$18 \mathrm{ng}\left(\mathrm{m}^{2} \mathrm{~d}\right)^{-1}\left(10 \pm 5.3 \mathrm{ng}\left(\mathrm{m}^{2} \mathrm{~d}\right)^{-1}\right)$. Different from TFA, particle

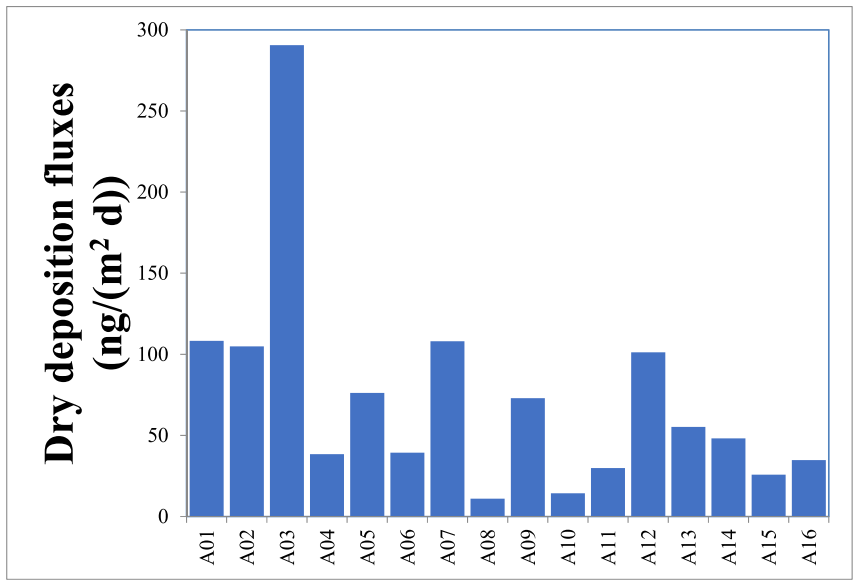

Fig. 3. Distribution of the dry deposition fluxes $\left(n g \cdot\left(m^{2} d\right)^{-1}\right)$ in the air above the Bohai and Yellow Seas.

deposition $(81 \% \pm 32 \%)$ was a higher percentage than gas deposition for $\Sigma$ i-PFASs. Cl-6:2 PFESA had the same deposition flux levels $\left(0.24 \pm 0.21 \mathrm{ng}\left(\mathrm{m}^{2} \mathrm{~d}\right)^{-1}\right)$ as PFHxS $\left(0.35 \pm 0.083 \mathrm{ng}\left(\mathrm{m}^{2} \mathrm{~d}\right)^{-1}\right)$. The deposition fluxes of $\Sigma$ n-PFASs ranged from $0.71 \mathrm{ng}^{2}\left(\mathrm{~m}^{2} \mathrm{~d}\right)^{-1}$ to $130 \mathrm{ng}\left(\mathrm{m}^{2} \mathrm{~d}\right)^{-1}$ (mean $21 \pm 31 \mathrm{ng}\left(\mathrm{m}^{2} \mathrm{~d}\right)^{-1}$ ), which were higher than Büsum, Germany $\left(1.3 \pm 0.63 \mathrm{ng}\left(\mathrm{m}^{2} \mathrm{~d}\right)^{-1}\right)$ (Wang et al., 2014b). The deposition fluxes of $\Sigma$ n-PFASs were lower than TFA (mean $\left.41 \pm 40 \mathrm{ng}\left(\mathrm{m}^{2} \mathrm{~d}\right)^{-1}\right)$ but higher than $\Sigma$ i-PFASs excluding TFA $\left(10 \pm 5.3 \mathrm{ng}\left(\mathrm{m}^{2} \mathrm{~d}\right)^{-1}\right)$. 8:2 FTOH possessed the highest fluxes of $15 \pm 31 \mathrm{ng}\left(\mathrm{m}^{2} \mathrm{~d}\right)^{-1}$, which was one or two orders of magnitude higher than other homologues. $\Sigma$ diPAPs fluxes $0.27 \pm 0.22 \mathrm{ng}\left(\mathrm{m}^{2} \mathrm{~d}\right)^{-1}$ were comparable to Cl-6:2 PFESA, and the particle deposition was the key process. 6:2 diPAP $\left(0.19 \pm 0.20 \mathrm{ng}\left(\mathrm{m}^{2} \mathrm{~d}\right)^{-1}\right)$ had higher fluxes than 8:2 diPAPs $\left(0.077 \pm 0.047 \mathrm{ng}\left(\mathrm{m}^{2} \mathrm{~d}\right)^{-1}\right)$.

The distributions of dry deposition fluxes $\left(\mathrm{ng} \cdot\left(\mathrm{m}^{2} \mathrm{~d}\right)^{-1}\right)$ are shown in Fig. 3. The highest flux $\left(290 \mathrm{ng}\left(\mathrm{m}^{2} \mathrm{~d}\right)^{-1}\right)$ was found at A03, at which the highest concentration of $\Sigma$ PFASs $\left(430 \mathrm{pg} \mathrm{m}^{-3}\right.$ ) was detected. Site A08 posed the lowest flux $\left(11 \mathrm{ng}\left(\mathrm{m}^{2} \mathrm{~d}\right)^{-1}\right)$ due to the low deposition velocity $\left(0.08 \pm 0.12 \mathrm{~cm} \mathrm{~s}^{-1}\right)$.

The n-PFASs could degrade in air and were then deposited into the water. For instance, 8:2 FTOH was a precursor of PFOA, and the contribution from atmospheric degradation was up to $6 \%$ (Wallington et al., 2006). Assuming 6\% PFOA was generated from 8:2 FTOH degradation, the indirect source fluxes of PFOA were

Table 1

Dry deposition fluxes (ng. $\left.\left(\mathrm{m}^{2} \mathrm{~d}\right)^{-1}\right)$ of PFASs in the air above the Bohai and Yellow Seas.

\begin{tabular}{|c|c|c|c|c|c|}
\hline Compound & Gas phase & Particle phase & Compound & Gas phase & Particle phase \\
\hline TFA & NA-150 $(44 \pm 40)$ & NA-5.9 $(3.1 \pm 1.6)$ & $6: 2$ diPAP & NA & NA-0.79 (0.19 \pm 0.20$)$ \\
\hline PFBA & NA-1.8 $(0.36 \pm 0.45)$ & $1.6-5.9(2.9 \pm 1.2)$ & $8: 2$ diPAP & NA & NA-0.21 $(0.078 \pm 0.047)$ \\
\hline PFPeA & NA- $0.62^{\mathrm{a}}$ & $0.26-1.1(0.51 \pm 0.19)$ & $\Sigma$ diPAP & NA & NA-0.92 $(0.27 \pm 0.22)$ \\
\hline PFHxA & NA-0.24 $(0.073 \pm 0.080)$ & NA-8.8 $(2.7 \pm 1.9)$ & 6:2 FTOH & $0.053-4.3(1.2 \pm 1.0)$ & NA \\
\hline PFHpA & NA-0.16 $(0.086 \pm 0.073)$ & $0.40-1.1(0.68 \pm 0.19)$ & $8: 2 \mathrm{FTOH}$ & $0.13-120(15 \pm 31)$ & NA-0.31 $(0.14 \pm 0.085)$ \\
\hline PFOA & NA-0.54 $(0.12 \pm 0.14)$ & $0.60-7.4(2.0 \pm 1.7)$ & 10:2 FTOH & NA-24 $(4.4 \pm 6.1)$ & NA-0.19 $(0.12 \pm 0.048)$ \\
\hline PFNA & NA-0.28 $(0.10 \pm 0.069)$ & $0.28-0.62(0.40 \pm 0.096)$ & $\Sigma$ FTOHs & $0.40-120(20 \pm 31)$ & NA-0.50 $(0.20 \pm 0.14)$ \\
\hline PFDA & NA & $0.057-0.19(0.10 \pm 0.033)$ & MeFOSA & NA-0.23 $(0.12 \pm 0.071)$ & NA \\
\hline PFUnA & NA- $0.091^{\mathrm{a}}$ & NA-0.19 $(0.095 \pm 0.037)$ & EtFOSA & NA-0.64 $(0.22 \pm 0.071)$ & NA \\
\hline PFDoA & NA & NA- $0.074^{\mathrm{a}}$ & ¿FOSAs & NA-0.87 $(0.23 \pm 0.23)$ & NA \\
\hline PFBS & NA & NA-0.29 $(0.016 \pm 0.071)$ & MeFOSE & NA-1.3 $(0.67 \pm 0.32)$ & NA \\
\hline PFHxS & $0.0041-0.12(0.038 \pm 0.028)$ & $0.21-0.45(0.31 \pm 0.076)$ & EtFOSE & NA & NA- $0.078^{\mathrm{a}}$ \\
\hline PFOS & $0.032-0.30(0.13 \pm 0.074)$ & $0.19-1.1(0.74 \pm 0.25)$ & $\Sigma F O S E s$ & NA-1.3 $(0.50 \pm 0.40)$ & NA \\
\hline Cl-6:2 PFESA & NA & $\mathrm{Na}-0.67(0.27 \pm 0.21)$ & $\Sigma$ n-PFASs & $0.71-120(21 \pm 31)$ & $0.073-0.50(0.21 \pm 0.15)$ \\
\hline$\Sigma$ i-PFAS (no TFA) & $0.076-4.0(0.77 \pm 0.97)$ & NA-17 $(11 \pm 3.9)$ & ¿PFASs & $5.7-270(60 \pm 65)$ & $0.085-19(12 \pm 5.6)$ \\
\hline ¿i-PFASs & $0.076-150(39 \pm 40)$ & $8.3-19(13 \pm 3.5)$ & & & \\
\hline
\end{tabular}

NA: Not available.

a Detectable in one sample. 
$0.91 \pm 1.8 \mathrm{ng}\left(\mathrm{m}^{2} \mathrm{~d}\right)^{-1}$. It is difficult to distinguish between the indirect and direct sources based on this study because the PFOA was quantified partly from the degradation of precursors at other air layers. However, the indirect source could not be ignored because i) not only 8:2 FTOH could degrade to PFOA., such as 10:2 FTOH and 8:2 diPAP, which were potential contributors of indirect sources (Ellis et al., 2004; Liu and Liu, 2016), and ii) the degradation of precursors will be strengthened by the enrichment of $\mathrm{OH}$ radicals, $\mathrm{Cl}$ atoms and high humidity in coastal environments (Ellis et al., 2004; Wallington et al., 2006). More studies should be conducted on PFAS degradation, partition and deposition behaviours in marine environments.

\section{Conclusion}

The concentrations and distributions of alternative and legacy PFASs in gas and particle phases were investigated in the semi-closed Bohai and Yellow Seas in China. The contributions of shorter chained substances were larger than those of the legacy $\mathrm{C}_{8}$ homologues. One alternative compound of PFOS, Cl-6:2 PFESA, was detected in the air particles, but the percentage of $\Sigma$ PFASs ( $2 \% \pm 1 \%$ ) was still lower than those of PFOS $(8 \% \pm 3 \%)$. The air mass origination analysis indicated that the air mass with the highest concentration of TFA was mainly from the air above the two seas, while the other PFASs were mainly from the Chinese mainland and the coast of South Korea. Dry deposition fluxes were estimated based on the field concentrations. This study suggested a feasible method for monitoring the dry deposition of contaminants in marine air.

\section{Acknowledgements}

This study was funded by the National Natural Science Foundation of China (No. 41603101, 41773138 and No.41573097) and the State Key Laboratory of Organic Geochemistry, GIGCAS (No. SKLOG201609). We are grateful for the field assistance from the crew of Research Vessel Dongfanghong 2 of the Ocean University of China.

\section{Appendix A. Supplementary data}

Supplementary data related to this article can be found at https:// doi.org/10.1016/j.atmosenv.2018.08.052.

\section{References}

Ahrens, L., Harner, T., Shoeib, M., Lane, D.A., Murphy, J.G., 2012. Improved characterization of gas-particle partitioning for per- and polyfluoroalkyl substances in the atmosphere using annular diffusion denuder samplers. ES T (Environ. Sci. Technol.) 46, 7199-7206.

Ahrens, L., Shoeib, M., Del Vento, S., Codling, G., Halsall, C., 2011a. Polyfluoroalkyl compounds in the canadian arctic atmosphere. Environ. Chem. 8, 399-406.

Ahrens, L., Shoeib, M., Harner, T., Lee, S.C., Guo, R., Reiner, E.J., 2011b. Wastewater treatment plant and landfills as sources of polyfluoroalkyl compounds to the atmosphere. Environ. Sci. Technol. 45, 8098-8105.

Antinolo, M., Bravo, I., Jimenez, E., Ballesteros, B., Albaladejo, J., 2017. Atmospheric chemistry of $\mathrm{E}$ - and $\mathrm{z}-\mathrm{CF} 3 \mathrm{CH}=\mathrm{CHF}(\mathrm{HFO}-1234 \mathrm{ze})$ : $\mathrm{OH}$ reaction kinetics as a function of temperature and UV and IR absorption cross sections. J. Phys. Chem. 121, 8322-8331.

Arp, H.P.H., Schwarzenbach, R.P., Goss, K.-U., 2008. Ambient gas/particle partitioning. 1. Sorption mechanisms of apolar, polar, and ionizable organic compounds. Environ. Sci. Technol. 42, 5541-5547.

Bao, J., Liu, L., Wang, X., Jin, Y.H., Dong, G.H., 2017. Human exposure to perfluoroalkyl substances near a fluorochemical industrial park in China. Environ. Sci. Pollut. Res. 24, 9194-9201.

Barber, J.L., Berger, U., Chaemfa, C., Huber, S., Jahnke, A., Temme, C., Jones, K.C., 2007. Analysis of per- and polyfluorinated alkyl substances in air samples from Northwest Europe. J. Environ. Monit. 9, 530-541.

Begley, T.H., Hsu, W., Noonan, G., Diachenko, G., 2008. Migration of fluorochemical paper additives from food-contact paper into foods and food simulants. Food Addit. Contam. 25, 384-390.

Benskin, J.P., Muir, D.C.G., Scott, B.F., Spencer, C., De Silva, A.O., Kylin, H., Martin, J.W., Morris, A., Lohmann, R., Tomy, G., Rosenberg, B., Taniyasu, S., Yamashita, N., 2012. Perfluoroalkyl acids in the atlantic and canadian arctic oceans. ES T (Environ. Sci. Technol.) 46, 5815-5823.
Bossi, R., Vorkamp, K., Skov, H., 2016. Concentrations of organochlorine pesticides, polybrominated diphenyl ethers and perfluorinated compounds in the atmosphere of North Greenland. Environ. Pollut. 217, 4-10.

Buck, R.C., Franklin, J., Berger, U., Conder, J.M., Cousins, I.T., de Voogt, P., Jensen, A.A., Kannan, K., Mabury, S.A., van Leeuwen, S.P.J., 2011. Perfluoroalkyl and polyfluoroalkyl substances in the environment: terminology, classification, and origins. Integr. Environ. Asses. 7, 513-541.

Chan, C.Y., Tang, J.H., Li, Y.S., Chan, L.Y., 2006. Mixing ratios and sources of halocarbons in urban, semi-urban and rural sites of the Pearl River Delta, South China. Atmos. Environ. 40, 7331-7345.

Chen, H., Han, J., Zhang, C., Cheng, J., Sun, R., Wang, X., Han, G., Yang, W., He, X., 2017a. Occurrence and seasonal variations of per- and polyfluoroalkyl substances (PFASs) including fluorinated alternatives in rivers, drain outlets and the receiving Bohai Sea of China. Environ. Pollut. 231, 1223-1231.

Chen, H., Wang, X.M., Zhang, C., Sun, R.J., Han, J.B., Han, G.C., Yang, W.C., He, X., 2017b. Occurrence and inputs of perfluoroalkyl substances (PFASs) from rivers and drain outlets to the Bohai Sea, China. Environ. Pollut. 221, 234-243.

Chen, H.T., Reinhard, M., Nguyen, T.V., You, L.H., He, Y.L., Gin, K.Y.H., 2017c. Characterization of occurrence, sources and sinks of perfluoroalkyl and polyfluoroalkyl substances (PFASs) in a tropical urban catchment. Environ. Pollut. 227, 397-405.

D'Eon, J.C., Crozier, P.W., Furdui, V.I., Reiner, E.J., Libelo, E.L., Mabury, S.A., 2009. Observation of a commercial fluorinated material, the polyfluoroalkyl phosphoric acid diesters, in human sera, wastewater treatment plant sludge, and paper fibers. Environ. Sci. Technol. 43, 4589-4594.

D'Eon, J.C., Mabury, S.A., 2007. Production of perfluorinated carboxylic acids (PFCAs) from the biotransformation of polyfluoroalkyl phosphate surfictants (PAPS): exploring routes of human contamination. Environ. Sci. Technol. 41, 4799-4805.

D'eon, J.C., Mabury, S.A., 2011. Exploring indirect sources of human exposure to perfluoroalkyl carboxylates (PFCAs): evaluating uptake, elimination, and biotransformation of polyfluoroalkyl phosphate esters (PAPs) in the rat. Environ. Health Perspect. 119, 344-350.

Dassuncao, C., Hu, X.D.C., Zhang, X.M., Bossi, R., Dam, M., Mikkelsen, B., Sunderland, E.M., 2017. Temporal shifts in poly- and perfluoroalkyl substances (PFASs) in North atlantic pilot whales indicate large contribution of atmospheric precursors. Environ. Sci. Technol. 51, 4512-4521.

De Silva, A.O., Allard, C.N., Spencer, C., Webster, G.M., Shoeib, M., 2012. Phosphoruscontaining fluorinated organics: polyfluoroalkyl phosphoric acid diesters (diPAPs), perfluorophosphonates (PFPAs), and perfluorophosphinates (PFPIAs) in residential indoor dust. Environ. Sci. Technol. 46, 12575-12582.

Deng, M., Wu, Y., Xu, C., Jin, Y., He, X., Wan, J., Yu, X., Rao, H., Tu, W., 2018. Multiple approaches to assess the effects of F-53B, a Chinese PFOS alternative, on thyroid endocrine disruption at environmentally relevant concentrations. Sci. Total Environ. 624, 215-224.

Draxler, R.R., Hess, G., 1997. Description of the HYSPLIT4 Modeling System.

Ellis, D.A., Mabury, S.A., Martin, J.W., Muir, D.C.G., 2001. Thermolysis of fluoropolymers as a potential source of halogenated organic acids in the environment. Nature 412 , 321-324.

Ellis, D.A., Martin, J.W., De Silva, A.O., Mabury, S.A., Hurley, M.D., Andersen, M.P.S., Wallington, T.J., 2004. Degradation of fluorotelomer alcohols: a likely atmospheric source of perfluorinated carboxylic acids. Environ. Sci. Technol. 38, 3316-3321.

Eriksson, U., Karrman, A., 2015. World-wide indoor exposure to polyfluoroalkyl phosphate esters (PAPs) and other PFASs in household dust. Environ. Sci. Technol. 49, 14503-14511.

Fromme, H., Wockner, M., Roscher, E., Volkel, W., 2017. ADONA and perfluoroalkylated substances in plasma samples of German blood donors living in South Germany. Int. J. Hyg Environ. Health 220, 455-460.

Ge, H., Yamazaki, E., Yamashita, N., Taniyasu, S., Ogata, A., Furuuchi, M., 2017. Particle size specific distribution of perfluoro alkyl substances in atmospheric particulate matter in Asian cities. Environ Sci-Proc Imp 19, 549-560.

Giesy, J.P., Naile, J.E., Khim, J.S., Jones, P.D., Newsted, J.L., 2010. Aquatic toxicology of perfluorinated chemicals. Rev. Environ. Contam. Toxicol. 202 (202), 1-52.

Heydebreck, F., Tang, J., Xie, Z., Ebinghaus, R., 2015. Alternative and legacy perfluoroalkyl substances: differences between European and Chinese river/estuary systems. Environ. Sci. Technol. 49, 8386-8395.

Hu, X., Wu, J., Zhai, Z., Zhang, B., Zhang, J., 2013. Determination of gaseous and particulate trifluoroacetic acid in atmosphere environmental samples by gas chromatography-mass spectrometry. Chin. J. Anal. Chem. 1140-1146.

Jahnke, A., Ahrens, L., Ebinghaus, R., Temme, C., 2007. Urban versus remote air concentrations of fluorotelomer alcohols and other polyfluorinated alkyl substances in Germany. Environ. Sci. Technol. 41, 745-752.

Jimenez, E., Gonzalez, S., Cazaunau, M., Chen, H., Ballesteros, B., Daele, V., Albaladejo, J., Mellouki, A., 2016. Atmospheric degradation initiated by $\mathrm{OH}$ radicals of the potential foam expansion agent, $\mathrm{CF} 3(\mathrm{CF} 2)(2) \mathrm{CH}=\mathrm{CH} 2$ (HFC-1447fz): kinetics and formation of gaseous products and secondary organic aerosols. Environ. Sci. Technol. 50, 1234-1242.

Lam, N.-H., Cho, C.-R., Lee, J.-S., Soh, H.-Y., Lee, B.-C., Lee, J.-A., Tatarozako, N., Sasaki, K., Saito, N., Iwabuchi, K., Kannan, K., Cho, H.-S., 2014. Perfluorinated alkyl substances in water, sediment, plankton and fish from Korean rivers and lakes: a nationwide survey. Sci. Total Environ. 491, 154-162.

Lee, H., D'Eon, J., Mabury, S.A., 2010. Biodegradation of polyfluoroalkyl phosphates as a source of perfluorinated acids to the environment. Environ. Sci. Technol. 44, 3305-3310.

Li, J., Del Vento, S., Schuster, J., Zhang, G., Chakraborty, P., Kobara, Y., Jones, K.C., 2011. Perfluorinated compounds in the asian atmosphere. Environ. Sci. Technol. 45, $7241-7248$. 
Li, J., Tang, J.H., Mi, W.Y., Tian, C.G., Emeis, K.C., Ebinghaus, R., Xie, Z.Y., 2018. Spatial distribution and seasonal variation of organophosphate esters in air above the Bohai and Yellow seas, China. Environ. Sci. Technol. 52, 89-97.

Lin, Y.F., Ruan, T., Liu, A.F., Jiang, G.B., 2017. Identification of novel hydrogen-substituted polyfluoroalkyl ether sulfonates in environmental matrices near metalplating facilities. Environ. Sci. Technol. 51, 11588-11596.

Liu, B., Zhang, H., Yao, D., Li, J., Xie, L., Wang, X., Wang, Y., Liu, G., Yang, B., 2015a. Perfluorinated compounds (PFCs) in the atmosphere of Shenzhen, China: spatial distribution, sources and health risk assessment. Chemosphere 138, 511-518.

Liu, B.L., Zhang, H., Yao, D., Li, J.Y., Xie, L.W., Wang, X.X., Wang, Y.P., Liu, G.Q., Yang, B., 2015b. Perfluorinated compounds (PFCs) in the atmosphere of Shenzhen, China: spatial distribution, sources and health risk assessment. Chemosphere 138, 511-518.

Liu, C., Liu, J.X., 2016. Aerobic biotransformation of polyfluoroalkyl phosphate esters (PAPs) in soil. Environ. Pollut. 212, 230-237.

Liu, W., Qin, H., Li, J., Zhang, Q., Zhang, H., Wang, Z., He, X., 2017. Atmospheric chlorinated polyfluoinated ether sulfonate and ionic perfluoroalkyl acids in 2006 to 2014 in Dalian, China. Environ. Toxicol. Chem. 36, 2581-2586.

Mahapatra, C.T., Damayanti, N.P., Guffey, S.C., Serafin, J.S., Irudayaraj, J., Sepulveda, M.S., 2017. Comparative in vitro toxicity assessment of perfluorinated carboxylic acids. J. Appl. Toxicol. 37, 699-708.

Martin, J.W., Ellis, D.A., Mabury, S.A., Hurley, M.D., Wallington, T.J., 2006. Atmospheric chemistry of perfluoroalkanesulfonamides: kinetic and product studies of the $\mathrm{OH}$ radical and $\mathrm{Cl}$ atom initiated oxidation of $\mathrm{N}$-ethyl perfluorobutanesulfonamide. Environ. Sci. Technol. 40, 864-872.

Metz, B., Kuijpers, L., Solomon, S., Andersen, S.O., Davidson, O., Pons, J., de Jager, D., Kestin, T., Manning, M., Meyer, L., 2000. IPCC/TEAP Special Report on Safeguarding the Ozone Layer and the Global Climate System: Issues Related to Hydrofluorocarbons and Perfluorocarbons, Cambridge, U.K. pp. 478.

Moeller, A., Ahrens, L., Surm, R., Westerveld, J., van der Wielen, F., Ebinghaus, R., de Voogt, P., 2010. Distribution and sources of polyfluoroalkyl substances (PFAS) in the River Rhine watershed. Environ. Pollut. 158, 3243-3250.

Mopper, K., Zhou, X., 1990. Hydroxyl radical photoproduction in the sea and its potential impact on marine processes. Science 250, 661-664.

Muller, C.E., Gerecke, A.C., Bogdal, C., Wang, Z.Y., Scheringer, M., Hungerbuhler, K., 2012. Atmospheric fate of poly- and perfluorinated alkyl substances (PFASs): I. Daynight patterns of air concentrations in summer in Zurich, Switzerland. Environ. Pollut. 169, 196-203.

Pankow, J.F., Bidleman, T.F., 1991. Effects of temperature, TSP and per cent non-exchangeable material in determining the gas-particle partitioning of organic compounds. Atmos. Environ. Part A. General Topics 25, 2241-2249.

Prevedouros, K., Cousins, I.T., Buck, R.C., Korzeniowski, S.H., 2006. Sources, fate and transport of perfluorocarboxylates. Environ. Sci. Technol. 40, 32-44.

Russell, M.H., Hoogeweg, G., Webster, E.M., Ellis, D.A., Waterland, R.L., Hoke, R.A., 2012. TFA from HFO-1234yf: accumulation and aquatic risk in terminal water bodies. Environ. Toxicol. Chem. 31, 1957-1965.

Shoeib, M., Harner, T., Ikonomou, M., Kannan, K., 2004. Indoor and outdoor air concentrations and phase partitioning of perfluoroalkyl sulfonamides and polybrominated diphenyl ethers. Environ. Sci. Technol. 38, 1313-1320.

Shoeib, M., Vlahos, P., Hamer, T., Peters, A., Graustein, M., Narayan, J., 2010. Survey of polyfluorinated chemicals (PFCs) in the atmosphere over the northeast Atlantic Ocean. Atmos. Environ. 44, 2887-2893.

Tian, Y., Yao, Y., Chang, S., Zhao, Z., Zhao, Y., Yuan, X., Wu, F., Sun, H., 2018. Occurrence and phase distribution of neutral and ionizable per-and polyfluoroalky substances (PFASs) in the atmosphere and plant leaves around landfills: a case study in Tianjin, China. Environ. Sci. Technol. 52, 1301-1310.

Trasande, L., Koshy, T.T., Gilbert, J., Burdine, L.K., Attina, T.M., Ghassabian, A., Honda, M., Marmor, M., Chu, D.B., Han, X.X., Shao, Y.Z., Kannan, K., 2017. Serum perfluoroalkyl substances in children exposed to the world trade center disaster. Environ. Res. 154, 212-221.
UNEP, 2017a. Chemicals Proposed for Listing under the Convention.

UNEP, 2017b. Listing of POPs in the Stockholm Convention.

Wallington, T.J., Hurley, M.D., Xia, J., Wuebbles, D.J., Sillman, S., Ito, A., Penner, J.E., Ellis, D.A., Martin, J., Mabury, S.A., Nielsen, O.J., Andersen, M.P.S., 2006. Formation of $\mathrm{C} 7 \mathrm{~F} 15 \mathrm{COOH}(\mathrm{PFOA})$ and other perfluorocarboxylic acids during the atmospheric oxidation of 8: 2 fluorotelomer alcohol. Environ. Sci. Technol. 40, 924-930.

Wang, P., Lu, Y.L., Wang, T.Y., Fu, Y.N., Zhu, Z.Y., Liu, S.J., Xie, S.W., Xiao, Y., Giesy, J.P., 2014a. Occurrence and transport of 17 perfluoroalkyl acids in 12 coastal rivers in south Bohai coastal region of China with concentrated fluoropolymer facilities. Environ. Pollut. 190, 115-122.

Wang, Z., Xie, Z.Y., Mi, W.Y., Moller, A., Wolschke, H., Ebinghaus, R., 2015a. Neutral poly/per-fluoroalkyl substances in air from the atlantic to the southern ocean and in antarctic snow. Environ. Sci. Technol. 49, 7770-7775.

Wang, Z., Xie, Z.Y., Moller, A., Mi, W.Y., Wolschke, H., Ebinghaus, R., 2014b. Atmospheric concentrations and gas/particle partitioning of neutral poly- and perfluoroalkyl substances in northern German coast. Atmos. Environ. 95, 207-213.

Wang, Z., Xie, Z.Y., Moller, A., Mi, W.Y., Wolschke, H., Ebinghaus, R., 2015b. Estimating dry deposition and gas/particle partition coefficients of neutral poly-/perfluoroalkyl substances in northern German coast. Environ. Pollut. 202, 120-125.

Wong, F., Shoeib, M., Katsoyiannis, A., Eckhardt, S., Stohl, A., Bohlin-Nizzetto, P., Li, H., Fellin, P., Su, Y.S., Hung, H., 2018. Assessing temporal trends and source regions of per- and polyfluoroalkyl substances (PFASs) in air under the Arctic Monitoring and Assessment Programme (AMAP). Atmos. Environ. 172, 65-73.

Wu, J., Martin, J.W., Zhai, Z., Lu, K., Li, L., Fang, X., Jin, H., Hu, J., Zhang, J., 2014. Airborne trifluoroacetic acid and its fraction from the degradation of HFC-134a in beijing, China. Environ. Sci. Technol. 48, 3675-3681.

Xie, S.W., Lu, Y.L., Wang, T.Y., Liu, S.J., Jones, K., Sweetman, A., 2013a. Estimation of PFOS emission from domestic sources in the eastern coastal region of China. Environ. Int. 59, 336-343.

Xie, S.W., Wang, T.Y., Liu, S.J., Jones, K.C., Sweetman, A.J., Lu, Y.L., 2013b. Industrial source identification and emission estimation of perfluorooctane sulfonate $\mathrm{n}$ hina. Environ. Int. 52, 1-8.

Xie, Z.Y., Zhao, Z., Moller, A., Wolschke, H., Ahrens, L., Sturm, R., Ebinghaus, R., 2013c Neutral poly- and perfluoroalkyl substances in air and seawater of the North Sea. Environ. Sci. Pollut. Res. 20, 7988-8000.

Yamasaki, H., Kuwata, K., Miyamoto, H., 1982. Effects of ambient temperature on aspects of airborne polycyclic aromatic hydrocarbons. Environ. Sci. Technol. 16, 189-194.

Yao, Y., Chang, S., Zhao, Y., Tang, J., Sun, H., Xie, Z., 2017a. Per- and poly-fluoroalkyl substances (PFASs) in the urban, industrial, and background atmosphere of Northeastern China coast around the Bohai Sea: occurrence, partitioning, and seasonal variation. Atmos. Environ. 167, 150-158.

Yao, Y.M., Chang, S., Sun, H.W., Gan, Z.W., Hu, H.W., Zhao, Y.Y., Zhang, Y.F., 2016. Neutral and ionic per- and polyfluoroalkyl substances (PFASs) in atmospheric and dry deposition samples over a source region (Tianjin, China). Environ. Pollut. 212, $449-456$.

Yao, Y.M., Chang, S., Zhao, Y.Y., Tang, J.H., Sun, H.W., Xie, Z.Y., 2017b. Per- and polyfluoroalkyl substances (PFASs) in the urban, industrial, and background atmosphere of Northeastern China coast around the Bohai Sea: occurrence, partitioning, and seasonal variation. Atmos. Environ. 167, 150-158.

Young, C.J., Furdui, V.I., Franklin, J., Koerner, R.M., Muir, D.C.G., Mabury, S.A., 2007. Perfluorinated acids in arctic snow: new evidence for atmospheric formation. Environ. Sci. Technol. 41, 3455-3461.

Yuan, Q., Ma, G.C., Xu, T., Serge, B., Yu, H.Y., Chen, J.R., Lin, H.J., 2016. Developing QSPR model of gas/particle partition coefficients of neutral poly-/perfluoroalkyl substances. Atmos. Environ. 143, 270-277.

Zhao, Z., Tang, J., Mi, L., Tian, C., Zhong, G., Zhang, G., Wang, S., Li, Q., Ebinghaus, R., Xie, Z., Sun, H., 2017. Perfluoroalkyl and polyfluoroalkyl substances in the lower atmosphere and surface waters of the Chinese Bohai Sea, Yellow Sea, and Yangtze River estuary. Sci. Total Environ. 599, 114-123. 